\title{
Estudio de conducción nerviosa en nervio mediano de lactantes desnutridos y normales
}

El retardo mental que se observa en una fracción importante de la población es una de las características más destacadas e indeseables de los países subdesarrollados. Otra de ellas es la desnutrición que afecta al mismo sector de la población y que golpea con especial crudeza a los niños en los primeros años de vida, dejando tras sí serias secuelas. Se ha sugerido que hay una relación causal entre el déficit nutricional grave sufrido durante el periodo de maduración rápida del encéfalo y el retardo mental que posteriormente se observa (1-4). Los cambios bioquími$\cos$ y morfologicos que se observan en el encéfalo en estas circunstancias han sido documentados (6-8).

Parece razonable suponer que si el tejido nervioso del sistema nervioso central puede ser dañado por la desnutrición severa, el del sistema nervioso periférico también puede serlo. Sin embargo, el sistema nervioso central no se presta fácilmente a mediciones objetivas, especialmente en lactantes, como no sean los criterios subjetivos y aproximativos que entregan el avalúo neurológico y el electroencefalograma. En cambio es mucho más fácil medir la integridad de los nervios periféricos a cualquier edad, ya que su única función que es la de conducir impulsos nerviosos, puede ser medida con objetividad.

Para este efecto se tomó el nervio mediano de niños desnutridos y normales entre 4 y 11 meses de edad. La elección del nervio mediano se basó en los estudios de Gamstorp (9) quien encontró que la velocidad de conducción motora se mantiene relativamente estable entre estas edades, en tanto que las del cubital y ciático poplíteo externo aumentan rápidamente en ese período dando así valores más variables que para mediano. Gamstorp y Shelburne (10) usaron un valor artificial que llamaron "velocidad de conducción sensitiva",

\footnotetext{
* Neurología, Departamento de Medicina, Universidad de Chlle,
} Sede Valparaíso. obtenido dividiendo la distancia entre el electrodo de estímulo y el electrodo de registro en la mano del niño por la latencia, vale decir, por el tiempo que toma el estímulo en recorrer esta distancia. Puesto que la latencia representa tiempo empleado en excitar nervios digitales a través de la picl, más conducción nerviosa a lo largo del nervio, más el tiempo empleado en atravesar hasta la piel de nuevo en el sitio de registro, este parámetro no es una medición real de velocidad de conducción en estructuras puramente nerviosas. Por otro lado como el tamaño de la mano varía en el período de edad estudiado, resulta más realista dividir la distancia por la latencia dando así un valor que puede ser usado como indicador siempre que las condiciones sean idénticas para todos los nervios estudiados. Se comparó también las latencias motoras y sensitivas para ambos grupos de niños.

Como criterio de desnutrición se usó la clasificación de Gómez, la cual si bien reconocidamente tiene limitaciones (11), provee un indicador del estado nutricional del niño. Se considera desnutrición de primer grado si el peso del niño se encuentra entre el 10 y 24 por ciento menos de lo esperado para su edad. Similarmente para desnutrición de segundo y tercer grados la pérdida varía entre 25 y 30 por ciento y más de 40 por ciento respectivamente. El porcentaje se calcula conociendo el peso de nacimiento del niño.

MATERIAL Y METodo. El material consistió en 24 niños de peso normal para su edad y 30 niños desnutridos en segundo y tercer grado, ninguno marásmico, siendo la mayoría de segundo grado. Las edades variaron entre $\operatorname{los} 4$ y 11 meses exceptuando un desnutrido de tercer grado que tenía poco más de doce meses. Todos los niños pesaron más de $2,500 \mathrm{Kg}$. al parto. En algunos de los niños normales se midió ambos nervios medianos dando un total de 32 nervios estu- 
diados; en los niños desnutridos todas las mediciones se hicieron a un solo lado. Todos los niños desnutridos fueron tomados del Servicio de Pediatría del Hospital Gustavo Fricke de Viña del Mar donde ingresaron casi todos por diarrea aguda y deshidratación. La medición se hizo generalmente entre el tercer y séptimo día de hospitalización cuando ya había pasado la diarrea aguda y los niños habían ganado algo de peso con el tratamiento. La clasificación de desnutrición en segundo o tercer grado se hizo basándose en el peso en el día del examen. La posibilidad de que en el lapso entre ingreso al hospital y medición hubiera variado la velocidad de conducción no se tomó en cuenta para los efectos de este trabajo. Los nifros normales fueron en parte referidos desde diversos consultorios periféricos donde acudieron a control rutinario y en parte tomados del Servicio de Pediatría donde ingresaron por afecciones intercurrentes agudas como infección respiratoria, urinaria, o digestiva. No fue incluído ningún niño que tuviera antecedentes familiares o propios de enfermedad neurológica ni tampoco si estaba en tratamiento con fármacos que reconocidamente pueden causar neuropatía periférica, como isoniazida. El examen neurológico rutinario fue normal en todos los niños incluídos. La distribución por edades se aprecia en la Tabla I. La temperatura del laboratorio se mantuvo en niveles constantes, con ambiente calefaccionado en invierno, y osciló entre los 19 y 23 grados centígrados. No se usó anestesia ni premedicación en ningún caso, y a veces el movimiento agitado del niño hizo imposible la determinación de algunos parámetros obligando a descartarlos; esto ocurrió si el niño que frecuentemente se dormía durante el examen despertaba antes de terminarlo.

Se utilizó un electromiógrafo Galileo $R$ 81 a con estimulador y cámara fotográfica. Para la conducción motora el nervio fue estimulado en la

\section{T A B L A I}

DISTRIBUCION POR EDAD DE LOS NINOS NORMALES Y DESNUTRIDOS

\begin{tabular}{ccc}
\hline $\begin{array}{l}\text { Meses de } \\
\text { edad }\end{array}$ & $\begin{array}{c}\text { Normales } \\
32 \text { nervios }\end{array}$ & $\begin{array}{c}\text { Desnutridos } \\
30 \text { nervios }\end{array}$ \\
\hline $4-4,9$ & 1 & 7 \\
$5-\mathbf{5 , 9}$ & 8 & 6 \\
$6-\mathbf{6 , 9}$ & 7 & 1 \\
$7-7,9$ & 4 & 2 \\
$8-8,9$ & 4 & 3 \\
$9-9,9$ & 5 & 6 \\
$10-10,9$ & 1 & 2 \\
$11-11,9$ & 2 & 2 \\
$12-12,9$ & & 1 \\
\hline
\end{tabular}

muñeca $\mathrm{y}$ en el codo con electrodos de plata envueltos en franela y empapados en suero fisiológico. Un rectángulo de metal aplicado al dorso de la muñeca se usó para poner a tierra la preparación. Los electrodos de registro fueron dos discos de metal de $8 \mathrm{~mm}$. de diámetro, uno puesto sobre el abductor corto del pulgar y el otro sobre el dorso de la primera falange del pulgar, sujetándolos con tela adhesiva y con pasta conductora interpuesta. El estímulo consistió en pulsos cuadrados de 0,4 a 0,8 milisegundos con 100 a $140 \mathrm{v}$ de intensidad, lo que fue siempre mayor al mínimo necesario para obtener máxima amplitud de respuesta. Tanto el tiempo de conducción obtenido estimulando la muñeca y registrando sobre la eminencia tenar (latencia motora) como el obtenido estimulando en el codo y registrando del mismo modo, se obtuvieron del registro foto gráfico que incorpora una constante conocida de tiempo.

Para la conducción sensitiva se usó placas de plata con pasta conducotra aplicadas a la muñeca; los electrodos de estímulo fueron bandas de plata de $2 \mathrm{~mm}$ de ancho, con el cátodo rodeando la falange proximal del dedo índice y el ánodo la falange distal. Todos los electrodos se untaron con pasta conductora, y las mediciones se hicieron siguiendo el esquema descrito. La distancia entre el anillo colocado en la falange proximal y la muñeca se midió siempre con la muñeca en dorsiflexión. El tiempo de conducción entre estos dos puntos (latencia sensitiva) no se obtuvo en tres casos normales en los que el potencial sensitivo se captó en el codo en vez de en la muñeca. Todos los trazados fotográficos fueron medidos por dos observadores independientemente y los trazados en que hubo discrepancia fueron eliminados. De las cifras finales para conducción motora y sensitiva se eliminaron los decimales tomando en vez el entero más próximo.

RESUltados. La Tabla II muestra los resultados obtenidos, de los que se desprende que hay retardo significativo en la conducción motora y la "conducción sensitiva" entre los dos grupos midiendo nervio mediano.

Se aprecia que para las latencias motora y sensitiva la diferencia no es significativa. En cambio la velocidad de conducción motora es significativamente diferente al $2 \%$, y la "velocidad de conducción sensitiva" es significativamente diferente al $1 \%$.

Discusion. Estos resultados deben considerarse como aproximativos puesto que la técnica tiene un reconocido margen de error. Algunos de los errores intrínsecos al método han sido comentados (12) y se asevera que pueden hacer variar en un $20 \%$ las cifras obtenidas. El margen de 
T A B L A I I

$\mathrm{X}$ : PROMEDIO; S: DESVIACION STANDARD; $\mathrm{N}: \mathrm{NU}-$ MERO DE CASOS; T: VALOR DE LA COMPARACION DE PROMEDIOS. LOS VALORES DE LAS LATENCIAS ESTAN EN MILISEGUNDOS; DE LAS VELOCIDADES EN METROS POR SEGUNDO

\begin{tabular}{|c|c|c|c|c|c|c|c|}
\hline & \multicolumn{2}{|c|}{ Normales } & \multirow[b]{2}{*}{$N$} & \multicolumn{3}{|c|}{ Desnutridos } & \multirow[b]{2}{*}{$t$} \\
\hline & $X$ & $S$ & & $X$ & $S$ & $N$ & \\
\hline $\begin{array}{l}\text { Latencia } \\
\text { motora }\end{array}$ & 2,4 & 0,439 & 25 & 2,5 & 0,351 & 25 & 1,240 \\
\hline $\begin{array}{l}\text { Velocidad de } \\
\text { conducción }\end{array}$ & & & & & & & \\
\hline motora & 38 & 7,304 & 25 & 33 & 4,883 & 25 & 2,545 \\
\hline Latencla & 2,4 & 0,229 & 21 & 2,4 & 0,392 & 24 & 0,500 \\
\hline $\begin{array}{l}\text { de conducción } \\
\text { sensitiva" }\end{array}$ & 31 & 4,335 & 24 & 27 & 4,019 & 24 & 3,211 \\
\hline
\end{tabular}

error puede ser reducido si se usan técnicas más refinadas, usando electrodos de aguja para estimular y registrar (13). Estos métodos no se usaron aquí. Nuestras cifras no son sin embargo muy diferentes de las obtenidas en otras casuísticas para conducción motora. Entre los 4 y 12 meses, Gamstorp obtiene un promedio de $40 \mathrm{~m} / \mathrm{seg}$. en fibras motoras de nervio mediano en tanto que nosotros obtenemos $38 \mathrm{~m} / \mathrm{seg}$, ambos en niños normales (9). Gamstorp y Shelburne usan un indicador de la velocidad de conducción sensitiva que es en realidad un valor artificial (10); nuestras cifras son más altas en metros por segundo y la validez de esta diferencia queda en suspenso.

Sachdev y su grupo en la India (14) midieron velocidad de conducción motora en nervios mediano y ciático poplíteo externo de 30 niños, todos mayores de 12 meses hasta 5 años de edad y encontraron retardo en la conducción en 12 . Todos estos niños padecían de kwashiorkor. Este, y el factor edad, no hace posible una comparación con nuestros resultados. Osuntokun en Nigeria (15) midió la velocidad de conducción motora en 13 niños con kwashiorkor en la elapa aguda. Presentaban ascitis, anemia e hipoproteinemia severas, y otros índices de severa deficiencia. Los nervios estudiados fueron cubital, mediano, y ciático poplíteo común y los pacientes tenían entre 18 meses y 5 años; de ellos 7 fallecieron antes de las 2 semanas de ingreso. En general encontró cifras significativamente más lentas en niños con kwashiorkor que en niños normales. Hizo las mismas mediciones en los niños que sobrevivieron 6 semanas después del ingreso encontrando una mejoría estadísticamente significativa en la con- ducción, y en estos casos las cifras alcanzadas luego del tratamiento no difieren de las de niños normales en forma significativa. En 2 de los pacientes fallecidos se examinó el nervio tibial anterior al microscopio sin encontrar un defecto apreciable de la mielina; Osuntokun se inclina a pensar en un defecto bioquímico que altera la conducción en el kwashiorkor. Pero la edad de su material y el extremo defecto nutricional hace que sus casos sean cualitativamente diferentes a los nuestros.

Una diferencia significativa de velocidad de conducción entre nin̄os normales y desnutridos lleva a pensar a priori en diferencias de contenido mielínico en los nervios periféricos de ambos grupos. Los niños aquí presentados eran mucho menores que los que figuran en otras casuísticas y fueron examinados cuando la etapa infecciosa aguda que motivó la hospitalización había pasado. Estaban clínicamente "normales" por lo tanto es improbable que sufrieran un imbalance bioquímice intercurrente. Creemos que en gran parte fue obviada la dificultad que ofrecería la variación fisiológica experimentada por la velocidad de conducción con el desarrollo natural del niño al tomar un grupo etario más limitado.

Es probable que la formación de mielina sea deficiente por lo menos en el sistema nervioso central de niños desnutridos y hay evidencia que así lo stigiere (6). Se ha encontrado que la mielina del encéfalo de niños muy desnutridos es culantitativamente menor pero cualitativamente igual a la de niños normales (7), sugiriéndose que la noxa actúa sobre los procesos que preceden a la mielinización. En ratas, la desnutrición durante el período crítico del desarrollo de nervios periféricos causa defectos en la acumulación de mielina, período que para esta especie transcurre en los primeros días de vida extrauterina (16). Los nervios periféricos humanos comienzan a mielinizarse entre la decimosexta y decimoctava semana de gestación y el proceso está completado normalmente al parto. Esto sugiere que la velocidad de coducción en fibras más veloces no debiera cambiar aún si hay desnutrición desde el comienzo de la vida extrauterina. Aún si esto resultara así, es probable que nuestro material contara con niños que sufrieron algún grado de desnutrición durante la gestación pese a haber nacido con un peso aparentemente normal. Todos los niños desnutridos que se examinaron venían del sector más desvalicio de la población, el cual arrastra esta tara de generación en generación. Una proporción de los niños desnutridos lo son a partir de la vida intrauterina $y$ es posible que este factor haya contribuído a causar la diferencia en la velocidad de conducción al determinar un defectuoso revestimiento mielínico en los nervios de los desnutridos. Alternativamente, no puede descartarse 
que la desnutrición severa influya en alguna otra forma para causar el retardo en conducción que se observó.

Nuestros resultados prestan apoyo a la hipótesis de que el daño experimentado en la desnutrición severa por el sistema nervioso central tiene su contrapartida, funcional por 10 menos, en la inervación periférica. En aquellas regiones del mundo donde la desnutrición infantil constituye uno de los problemas más serios que enfrenta la comunidad, dificultando incluso la lucha de esta contra el subdesarrollo, existe una real necesidad de tener parámetros neurofisiológicos capaces de evaluar los diversos métodos que se usen para combatirla. Los estudios de conducción en nervios periféricos podrían ser una solución a esta problemática, usados seriadamente $\mathrm{y}$ en grupos de experimentación suficientemente grandes.

\section{RESUMEN}

Se plantea la hipótesis de que el daño que la desnutrición severa inflige al sistema nervioso central en lactantes tiene su contrapartida en el sistema nervioso periférico. Se hacen estudios de conducción nerviosa en nervio mediano de niños normales y desnutridos de 4 a 11 meses. Se estudió 32 nervios de niños normales y 30 nervios de niños desnutridos en segundo y tercer grado. En dos parámetros, la velocidad de conducción motora y la "velocidad de conducción sensitiva", un valor artificialmente obtenido, hay retardo significativo en la conducción. Se postula un defecto de la mielina. Se sugiere que este método ofrece un indicador neurofisiológico útil para estimar grado de lesión infligido a estructuras nerviosas en lactantes, en los que el sistema nervioso central no es facilmente asequible.

\section{SUMMARY}

Damage to the central nervous system in severe malnutrition is recognized and it seems logical to suppose that the peripheral nervous system is likewise affected. Nerve conduction studies in the median nerve of undernourished and normal children aged 4 to 11 months are carried out. 32 nerves of normal children and 30 nerves of second and third degree malnourished children are studied. Motor conduction velocity and "sensory conductio velocity", an artificial value, show significant delay in undernourished children. A defect of myelin function is suggested. It is suggested that this method offers a useful neurophysiological index in the estimation of damage undergone by nervous structures shortly after birth when the central nervous system is not easily accesible to investigation.

\section{REFERENCIAS}

1.-Dobbing J. Undernutrition and the developing brain: the relevance of animal models to the human problem. Am J. Dis. Child. 120: 411, 1970.

2.- Stoch $M B$, Smythe $P M$. Does undernutrition during infancy inhibit brain growth and subsequent intellectual development? Arch. Dis. Child. 38: 546, 1963.

3.- Cravioto J., De Licardie ER, Birch HG. Nutrition, growth and neurointegrative development: an experimental and ecologic study. Pediatrics 38: 319, 1966.

4.-Mönckeberg F. Malnutrition and mental behavior. Nutr. Rev. 27: 191, 1969.

5.--Rosso P., Hormazábal J., Winnick M. Changes in brain weight, cholesterol, phospholipid, and DNA content in marasmic children. Am J. Clin. Nutr. 23: $1275,1970$.

6.- Fishman MA., Prensky AL., Dodge PR. Low contents of cerebral lipids in infants suffering from malnutrition. Nature (Lond) 221: 552, 1969.

7.-Fox JH., Fishman MA., Dodge PR., Prensky AL. The effect of malnutrition on human central nervous system myelin. Neurology 22: 1213, 1972.

8.-Winnick M., Rosso P. Effects of severe early malnutrition on cellular growth of human brain. Pediat. Res. 3: 181, 1969.

9.-Gamstorp I. Normal conduction velocity of ulnar, median, and peroneal nerves in infancy, childhood, and adolescence. Acta Pediat. Scand. Suppl. 146: 68, 1963.

10.-Gamstorp 1., Shelburne S. A. Peripheral sensory conduction in ulnar and median nerves of normal infants, children, and adolescents. Acta Pediat. Scand. 54: 309, 1965.

11.-Meneghello J. Pediatría, Tomo I, Cap. 10. Edit. Inter-Médica. Buenos Aires, 1972.

12.- Campbell EDR. Peripheral neuropathy: electrodiagnostic aspects. Proc. roy Soc. Med. 64: 293, 1971.

13.-Wagner AL., Buchthal F. Motor and sensory conduction in infancy and childhood: a reappraisal. Develop Med. Child. Neurol. 14: 189, 1972.

14.-Sachdev KK., Taori GM., Pereira SM. Neuromuscular status in protein-calorie malnutrition. Neurology, 21: 801, 1971.

15.-Osuntokun BO. Motor nerve conduction in kwashiorkor (protein-calorie deficiency) before and after treatment. Afr. J. Med. Sci. 2: 109, 1971.

16.- Hedley-White ET. Myelination of rat sciatic nerve: comparison of undernutrition and cholesterol biosynthesis inhibition. J. Neuropathol Exptal. Neurol. 32: 284, 1973.

Se agradece a la Sra. Erika Himmel, Directora del Instituto de Investigaciones Estadisticas de la Universidad de Chile $y$ al Dr. F. Monckeberg por su apoyo; asimismo a los integrantes del Servicio de Pediatria del Hospital G. Fricke de Viña del Mar por su colaboración. 